\title{
Study of stud shear connectors behaviour in composite beams with profiled steel sheeting
}

Estudio del comportamiento de conectores tipo perno en vigas compuestas con lámina nervada

Jorge Douglas Bonilla Rocha (Main and Correspondent Author) Universidad de Ciego de Ávila, Departamento de Matematicas. Carretera a Morón km 9 1⁄2, Ciego de Ávila, Cuba. Fono: +53-33-266211 jorgedbr@unica.cu

\section{Luciano M. Bezerra}

University of Brasília, Department of Civil Engineering, Brazil Imbz@unb.br

\section{Rafael Larrúa Quevedo}

University of Camagüey, Department of Civil Engineering, Cuba rafael.larrua@reduc.edu.cu

\begin{abstract}
This work presents an FE study concerning the prediction of the shear resistance of headed stud connectors in composite beams with profiled steel sheeting subjected to static load. To confirm the FE simulation for the determination of the shear resistance of stud connectors, many experimental push-out tests whose results are available in the literature were used as a database. The FE simulations took into account the influence of many physical and mechanical parameters that affect the shear resistance of the stud connectors and such parameters are reported in the course of this paper. The prediction of the shear resistance of such studs is also calculated from currently used Standards, such as: AISC-LRFD and Eurocode-4. This research proposes new formulations for the prediction of the shear resistance and the results show that the proposed formulations significantly improve the prediction of the shear resistance of headed stud connectors subjected to static load.
\end{abstract}

Keywords: composite structures, shear studs, shear connectors, steel deck slab, composite beam.

\section{Introduction}

This research focuses upon the determination of the shear resistance of headed stud connector in composite steelconcrete beams where the steel profiled decking with trapezoidal transverse section is used for the concrete slab. Moreover, the ribs of the steel deck (profiled steel sheeting) are oriented perpendicular to the longitudinal axis of the supporting steel I-beam (see Fig. 1).

Based upon research conducted by the authors of this work, especially in the studies carried out by Bonilla (2008), Larrúa et al. (2009) as well as by other international researchers, particularly the works by Jayas \& Hosain (1988), Robinson (1988), Lyons \& Murray (1994), Johnson \& Yuan(1998), Rambo-Roddenberry (2002); it is possible to conclude that the predicting expressions for the determination of the shear resistance of the headed stud are not reliable for steelconcrete composite beams with concrete slabs made of steel profile decking with ribs perpendicular to the longitudinal axis of the steel beam.

Considering the expressions from prestigious international Standards such as the AISC-LRFD (2010) and the Eurocode- 4 (EN-1994-1-1:2004) specifications, one can conclude that in some cases the ultimate capacity of the headed stud shear connectors is excessively underestimated and in other cases excessively overestimated, thus generating the need to improve the current expressions for predicting the strength of such stud shear connector.

Due to the effectiveness of the push-out tests and the validity that has preserved their application internationally, since the rise in the use of composite structures; the direction adopted in this paper so as to understand the behavior of stud shear

\author{
Carlos Alexander Recarey Morfa \\ Central University of Las Villas, Department of Civil Engineering, Cuba \\ recarey@uclv.edu.cu
}

\section{Enrique Mirambell Arrizabalaga}

Polytechnic University of Catalunya, Department of Construction Engineering, Spain

enrique.mirambell@upc.edu

\author{
Manuscript Code: 546 \\ Date of Reception/Acceptance: 01-11-2014/01-12-2015
}

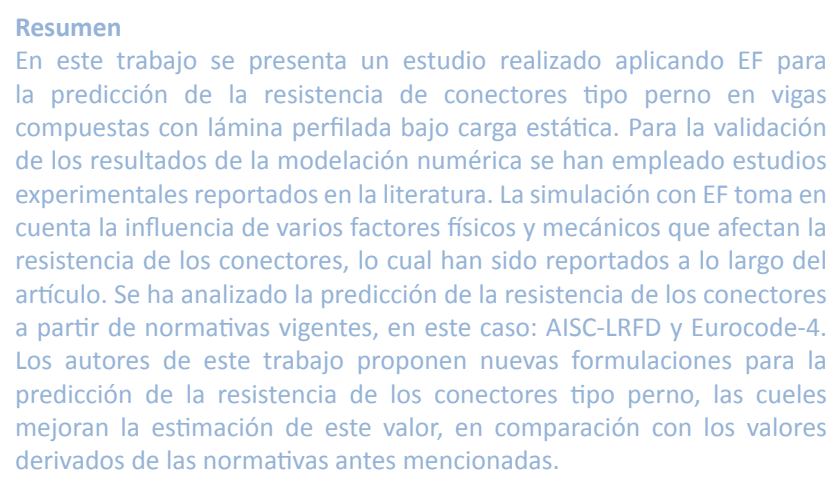

derivados de las normativas antes mencionadas.

Palabras Claves: estructuras compuestas, conector pernos, conexión, lamina nervada, viga compuesta.

connectors has been to focus upon the results from numerical simulations of push-out tests. Such experimental results, together with other experimental and numerical verifications done by different international researchers (Jayas \& Hosain, 1988; Robinson, 1988; Lyons et al., 1994; Rambo-Roddenberry, 2002), provide in this research a data base for calibration and validation for the numerical FE models used here in this paper. A detailed list of the simulation work, FE model calibrations and validations, as well as a comprehensive numerical FE simulations for determining studs ultimate strength, can be found in especially in Bonilla (2008) and in Bonilla et al. (2010) and will not be repeated in this paper.

The FE technique has become a powerful tool for analyzing structures and provides supplementary information to representative tests. Distributed stress and strain information is not easily obtainable from experiments, and, therefore, numerical investigation may be used to provide supplementary data to improve understanding. For the past five years, different international researchers have utilized FE simulation to model composite structures with very good results (Lawson \& et. al., 2013; Zheng, \& et. al., 2014; Hernández, \& et. al., 2014; Bonilla \& et. al., 2015).

The main objective of this paper is to report a wide variety of numerical and experimental results for the shear resistance of headed stud connectors in composite concrete-steel beams with concrete slab made from steel deck whose ribs are perpendicular to the I-beam. Finally, from these results, the authors propose new formulations to better predict the shear resistance of such connectors. 
AISC-LRFD (2010) defines expression (1) for calculating the shear resistance for headed stud connectors in composite section made up of concrete slabs using steel deck and steel I-beam.

$Q_{x=}=0.5 \cdot A_{s e} \cdot \sqrt{f_{c}^{\prime} \cdot E_{\varepsilon}} \leq R_{g} \cdot R_{g} \cdot A_{s \varepsilon} \cdot F_{z}$

Where: Asc is the area of the stud cross-section (in2); f'c is the strength specified for concrete in compression (ksi); Ec is the modulus of elasticity for concrete (ksi); Fu is the minimum strength specified for the connector in tension (ksi). Rg and $\mathrm{Rp}$ are reduction coefficients. Eurocode-4 (EN-1994-1-1:2004) defines expression (2) for calculating the shear resistance for headed stud connectors in the composite section made up of solid concrete slabs.

$Q_{s \varepsilon}=0.37 \cdot \alpha \cdot A_{s \varepsilon} \cdot \sqrt{f_{c k} \cdot E_{\varepsilon}} \leq 0.8 \cdot A_{s \varepsilon} \cdot f_{z}$

Where: Asc is the stud connector's cross-sectional area in (m2); $\propto$ is reduction coefficient; fck is the characteristic compressive strength of the concrete ( $\mathrm{MPa})$; $\mathrm{Ec}$ is the modulus of elasticity of the concrete (MPa); fu is the ultimate tensile strength of the stud steel (MPa). For composite section made of concrete slab with the steel deck ribs orientated perpendicular to the I- beam axis, it is necessary to reduce the value obtained in expression (2) by multiplying this value by the reduction coefficient (kt). The method proposed by Rambo-Roddenberry (2002) consists: (1) For headed shear studs in profiled steel decks of $51 \mathrm{~mm}$ and $76 \mathrm{~mm}$ in height where the relation between the connector diameter ( $d$ ) and the I-beam flange thickness (tf), that is (d/tf) $\leq 2.7$, the following expression is proposed (3):

$Q_{s}=R_{g} \cdot R_{x} \cdot R_{d} \cdot A_{x} \cdot F_{s}$

In expression (3), $\mathrm{Rp}$ is the reduction coefficient that considers the stud position inside the steel deck rib and takes the value $\mathrm{Rp}=0.68$ for the favorable position (SP) [emid-hr $\geq 56 \mathrm{~mm}$ (2.2 in)]; Rp $=0.48$ for the unfavorable position (WP) (emid-hr $<56 \mathrm{~mm}$ ) and $\mathrm{Rp}=0.52$ for headed shear studs in staggered position - where emid-hr is the average distance from the stud to the profile decking sheet - see Fig. $1 . \mathrm{Rn}$ is a reduction coefficient that considers the number of connectors inside the steel deck ribs and takes the value $\mathrm{Rn}=1.0$ for one stud per rib or for studs in StP. Rn $=0.85$ for two studs per steel deck rib. $\mathrm{Rd}$ is a coefficient that takes into consideration the thickness of the profile decking sheet and assumes the value $\mathrm{Rd}=1.0$ for the favorable position of studs and all sheet thicknesses (or sheet number or gauge as known in practice). $\mathrm{Rd}=0.88$ for studs placed in WP inside the ribs and deck sheet \#22. Rd $=1.0,1.05$ and 1.11, for sheet gauges, respectively, \#20, \#18 and \#16. (2) For headed studs in profile decking sheet with heights of $25 \mathrm{~mm}$ and $38 \mathrm{~mm}$ and where the relation between the stud diameter and the steel deck thickness $(d / t f) \leq 2.7$, the following expression is (4):

$Q_{s c}=R_{n} \cdot 3.08 \cdot e^{0.048 \cdot A_{S C} \cdot F_{U}}$

In expression (4), $\mathrm{Rn}$ takes the value $\mathrm{Rn}=1.0$ or $\mathrm{Rn}=0.85$, respectively, for one or two headed stud per steel deck rib. When $(\mathrm{d} / \mathrm{tf}) \leq 2.7$ is not satisfied, the values obtained in expressions ( 3 ) and (4) should be multiplied, by the factor $(1.5 \cdot[(d / t f)-2.7])$.

\section{Description of the Problem}

\section{Comparing shear resistance of connectors}

In this section, the precision in predicting the shear resistance of stud connectors, considering the three procedures described before is examined. In all cases, a comparison between the estimated value and the experimental shear resistance is shown.

Figure 2. Prediction of the stud connection resistance in steel deck with 25
$\mathrm{~mm}$ height based upon AISC-LRFD (2010), EC-4 (2004), Rambo-Roddenberry (2002). Source: Self-elaboration, 2013.

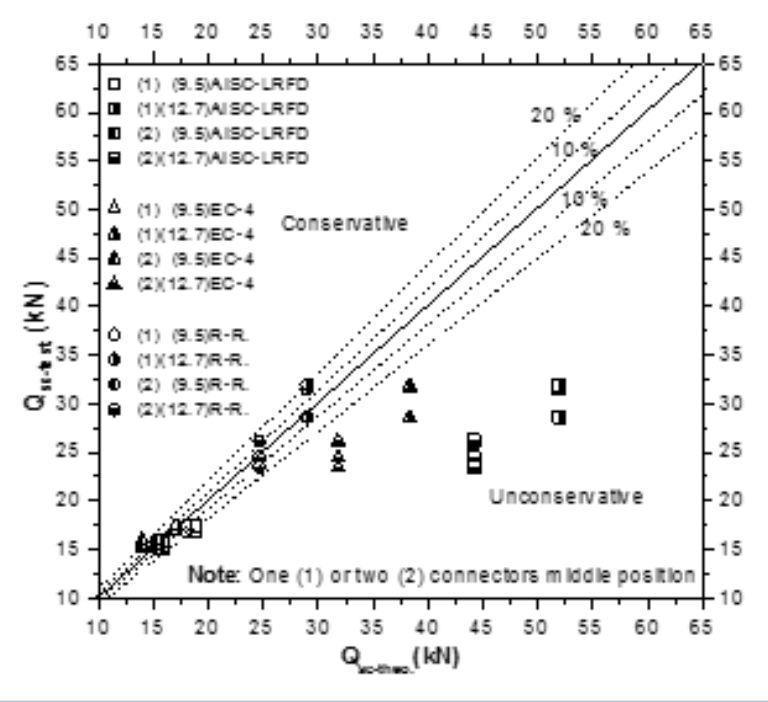

Figure 1. Frontal and lateral views of composite specimen, representing the stud positions with respect to the steel deck: (a) Strong Position (SP), (b) Weak Position (WP), (c) Staggered Position (StP). Source: Self-elaboration, 2008.

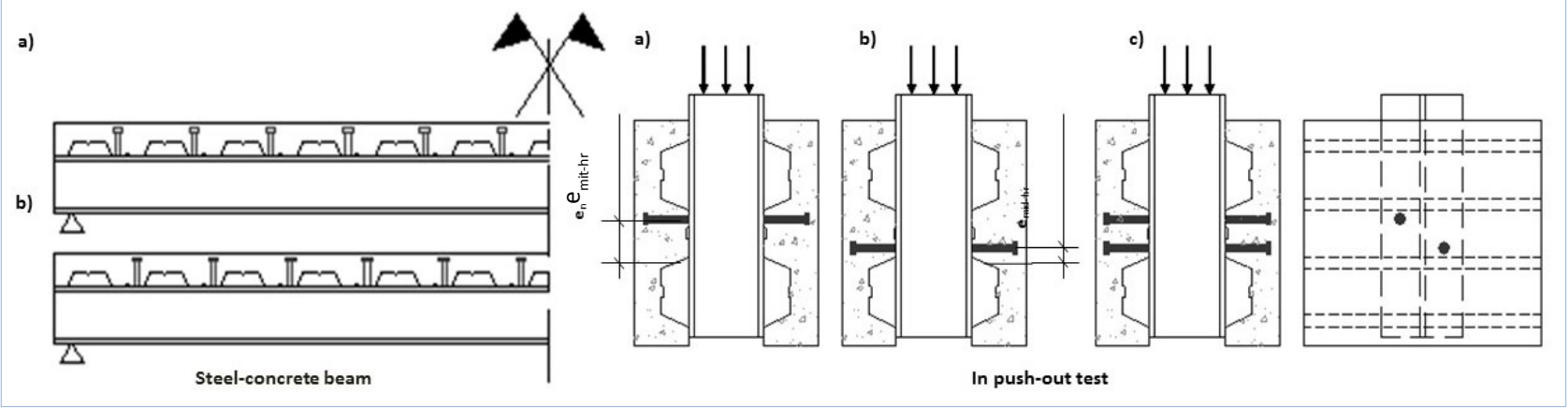


In Figs. 2 to 5 , the symbol $(X) Y(Z)$ means $X=$ number of studs, $Y=$ stud position, $Z$ = stud diameter. In such figures, the trend (conservative, unconservative), in the shear resistance value can be noticed considering the three methods studied in the section before. In Fig. 2, it is interesting to see how the RamboRoddenberry (2002) procedure is accurate for steel deck with height of $25 \mathrm{~mm}$, but not so for steel deck with height of $51 \mathrm{~mm}$ (see Fig. 5). The shear resistance is overestimated especially for connectors in SP. However, for 76 and $80 \mathrm{~mm}$ height of the steel deck ribs, the procedures analyzed showed a clear trend to overestimate the stud shear resistance (see Fig. 5). The AISC-LRFD (2010), generally, overestimates the stud shear resistance for various types of steel deck, particularly for the $76 \mathrm{~mm}$ deck height (see Fig. 3).

The prediction according to the Eurocode-4 (EN-1994-11:2004) shows some dispersion when compared to the other methods analyzed (Rambo-Roddenberry, 2002) and AISC-LRFD (2010). On the one hand, very conservative results are obtained, in other cases, as with studs in WP; the shear resistance is overestimated (unconservative results) as can be seen in Figs. 2 and 4. Given the previous analysis, better calculation expressions are required for the stud shear resistance for deeper profiles. In the literature, there is extensive experimental work for steel deck with $51 \mathrm{~mm}$ height; however, this does not occur for steel profiles with greater heights. Rambo-Roddenberry (2002) generated expressions based upon regression models that scarcely used $76 \mathrm{~mm}$ steel profiles. Rambo-Roddenberry's method overestimates the stud shear resistance for those deck height used (see Fig. 5(b)).

Figure 3. . Prediction of the shear resistance according to AISC-LRFD (2010)
in steel decks with heights ( $\mathrm{hr}$ ): (a) $\mathrm{hr}=51 \mathrm{~mm}$ and (b) $\mathrm{hr}=76$ and $80 \mathrm{~mm}$. in steel decks with heights (hr):
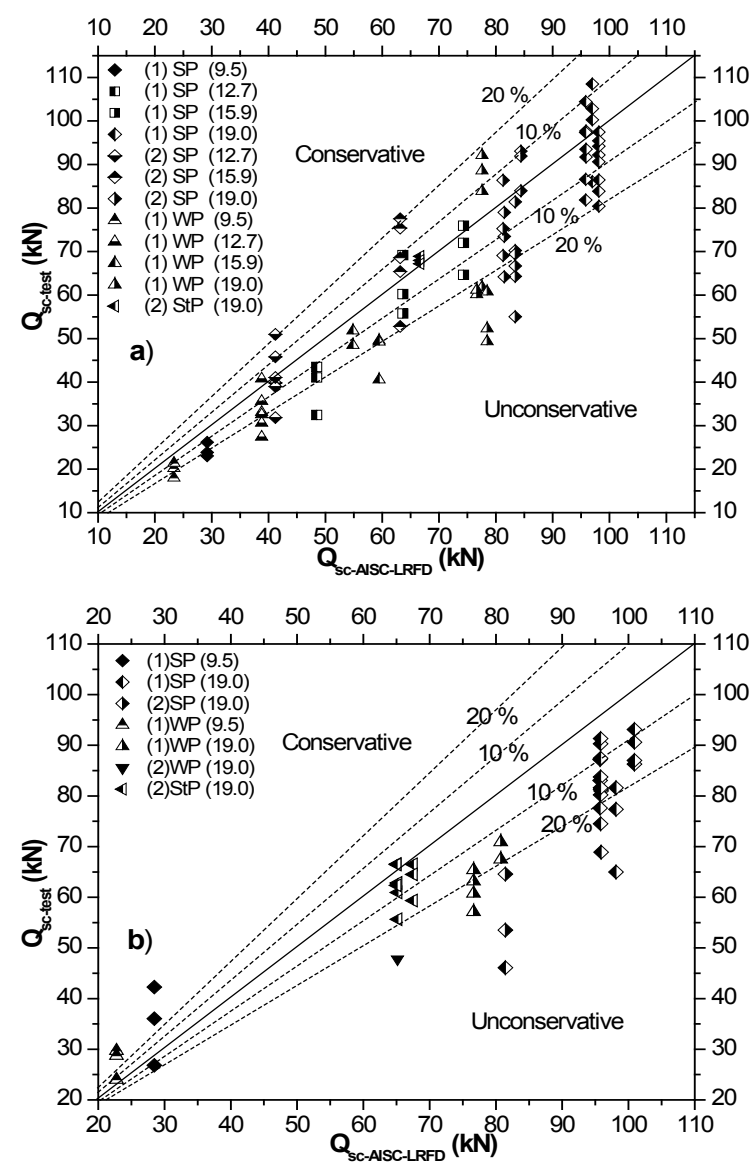

Figure 4. Prediction of the shear resistance according to EC-4 (2004) for steel deck with different heights ( $\mathrm{hr}$ ): (a) $\mathrm{hr}=51 \mathrm{~mm}$ and (b) $\mathrm{hr}=76$ and $\mathrm{hr}=80 \mathrm{~mm}$. Source: Self-elaboration, 2013
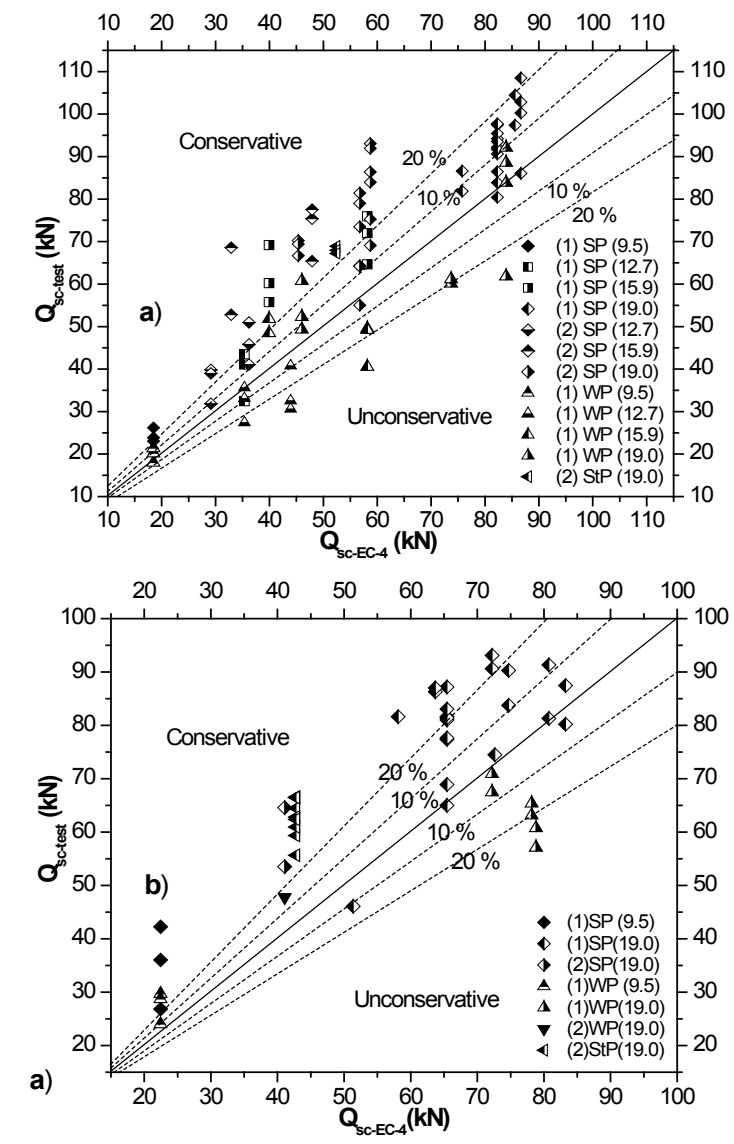

Figure 5. Prediction of the shear resistance based upon Rambo-Roddenberry's Method (2002) for Steel deck with different heights (hr): (a) hr= $51 \mathrm{~mm}$ and (b) $\mathrm{hr}=76$ and $80 \mathrm{~mm}$. Source: Self-elaboration, 2013 .
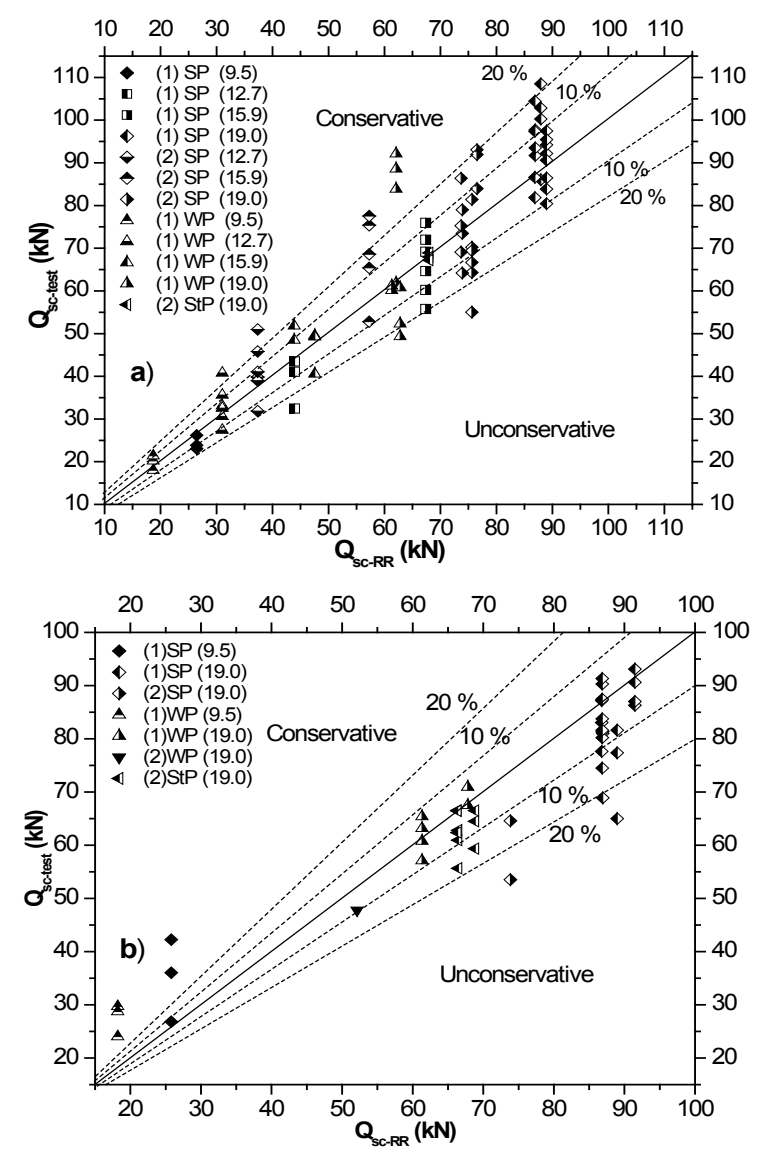
Finally, it is noticed that in the studies presented in this section, the stud resistances were analyzed considering studs in different positions (SP, WP, StP) and with different diameters [9.5 (3/8), $12.7(1 / 2), 15.9$ (5/8) and 19 mm (3/4 in)] (see Fig.: $2,3,4,5$ and 7$)$.

\section{Methodology}

\section{Compressive strength of concrete}

The effect of compressive strength of concrete $\left(f^{\prime} c\right)$ on stud shear resistance has been studied numerically by Bonilla (2008). From these results, it became evident that this parameter significantly influences the shear resistance of the stud connections - mainly when the connectors are placed in SP or in StP. Therefore, the authors of this work consider that the factor ( $\left.f^{\prime} c\right)$ should be taken into account for the calculation procedure of the shear resistance of the studs. The expression developed by Rambo-Roddenberry (2002) does not consider the concrete effect on the connection behavior.

\section{Thickness of the steel deck sheet}

Throughout the research developed by Lyons et al. (1994), it is possible to verify that specifically with studs in an unfavorable position (WP), there are increases in the shear resistance of a stud when the thickness of the steel deck increases, this is not the case with studs in the favorable position (SP) (see Table 1).

Bonilla (2008) accomplished numerical studies in which there are similar conclusions to those achieved by Lyons et al. (1994). From these studies, a coefficient for the shear resistance of stud $(\propto 3)$ is derived and will be considered for studs in unfavorable position in the new procedure for the calculation of shear resistance of stud connectors that will be proposed by the authors in section: results of this article.

\section{Connector cross-section and tensile strength}

The cross-section of the connector influences the shear resistance of stud considerably and this has been studied numerically by Bonilla (2008). That conclusion is also in agreement with experimental studies conducted by various researchers such as Rambo-Roddenberry (2002) and Lyons et al. (1994). Additionally, it must be pointed out that stud ultimate tensile strength $(\mathrm{Fu})$ does not significantly influence the shear resistance of stud connectors in strong or weak positions.

\section{Shear connector height}

In order to investigate the influence of the connector height (hc) on its shear resistance, experimental studies developed by Lyons et al. (1994) are taken as the principal basis noting also that they used $19 \mathrm{~mm}$ diameter shear connectors placed in favorable (SP) and in staggered positions (StP), as well as steel decks with $51 \mathrm{~mm}$ ( 2 in) and $76 \mathrm{~mm}$ (3 in) heights (hr). From these studies, it can be concluded that the increase in the shear resistance of stud connectors is hardly significant with the varying relation ( $\mathrm{hc} / \mathrm{hr}$ ). Hence, it is convenient not to include this parameter as a variable in the calculation of the shear resistance of stud and this is in agreement with the conclusions from Rambo-Roddenberry's (2002) research.

\section{Steel deck height}

Eurocode 4 (EN-1994-1-1:2004) and expression (3) (for $\mathrm{hr}=51$ and $76 \mathrm{~mm}$ ) and expression (4) (for $\mathrm{hr}=25 \mathrm{~mm}$ )), proposed by Rambo-Roddenberry (2002) includes the steel deck height as a parameter in formulating the expression to calculate the shear resistance of stud connectors. Throughout the studies by Bonilla (2008) and other experimental observations (Robinson, 1988; Sublett, Easterling \& Murray, 1992; Lyons et al. 1994, Rambo- Roddenberry 2002), the steel deck height parameter influences the shear resistance of stud connectors.

\section{Shear connector position}

Most steel deck has a central stiffener in the middle of the deck rib and studs welded off-center of the deck rib may be in strong or weak positions. In the expressions in AISC-LRFD (2010) and Rambo-Roddenberry (2002), the stud location inside the steel deck rib is taken into account. In fact, from the experimental studies carried out by Rambo-Roddenberry (2002) and also supported by experimental investigations from Robinson (1988), Sublett et al. (1992), Johnson \& Yuan (1998); the influence of the stud position on its shear resistance has been widely confirmed.

According to Rambo-Roddenberry (2002), the studs can be in a strong position (SP) when emid-hr $\geq 56 \mathrm{~mm}$ ( $2.2 \mathrm{in}$ ), and in a weak position (WP) when emid-hr $<56 \mathrm{~mm}$. Note that emid-hr

\begin{tabular}{|c|c|c|c|c|c|c|}
\hline Source & Specimen & $\begin{array}{l}\text { Deck thickness } \\
(\mathrm{mm})\end{array}$ & Deck gauge & $\begin{array}{l}\text { Qsc-test-5.08 } \\
(\mathrm{kN})\end{array}$ & $\begin{array}{l}\text { Qsc-test-5.08 } \\
\text { (means) } \\
(\mathrm{kN})\end{array}$ & $\begin{array}{c}\text { Qsc-test-5.08 (means) / } \\
\text { Qsc-test-5.08 (means), \# } 20\end{array}$ \\
\hline \multirow{12}{*}{$\begin{array}{l}\text { Lyons et al. } \\
(1994) \\
\text { f'c }=18.75_{(\mathrm{MPa})}\end{array}$} & S20-D40 & 0.762 & \multirow{3}{*}{22} & 48.70 & \multirow{3}{*}{47.74} & \multirow{3}{*}{0.88} \\
\hline & S20-D41 & 0.762 & & 48.75 & & \\
\hline & S20-D42 & 0.762 & & 45.77 & & \\
\hline & S21-D43 & 0.914 & \multirow{3}{*}{20} & 49.33 & \multirow{3}{*}{54.11} & \multirow{3}{*}{1.00} \\
\hline & S21-D44 & 0.914 & & 52.26 & & \\
\hline & S21-D45 & 0.914 & & 60.76 & & \\
\hline & S22-D46 & 1.219 & \multirow{3}{*}{18} & 47.46 & \multirow{3}{*}{56.67} & \multirow{3}{*}{1.05} \\
\hline & S22-D47 & 1.219 & & 63.12 & & \\
\hline & S22-D48 & 1.219 & & 59.43 & & \\
\hline & S23-D49 & 1.524 & \multirow{3}{*}{16} & 66.81 & \multirow{3}{*}{59.94} & \multirow{3}{*}{1.11} \\
\hline & S23-D50 & 1.524 & & 52.08 & & \\
\hline & S23-D51 & 1.524 & & 60.94 & & \\
\hline
\end{tabular}

Qsc-test-5.08 = Maximum shear resistance for a $5.08 \mathrm{~mm}(0.2 \mathrm{in})$ vertical displacement in the push-out test showing punching failure of the steel deck (Lyons et al., 1994).; Qsc-test-5.08 (means) = Average of the shear resistance; Qsc-test-5.08 (means), \# $20=$ Shear resistance for steel deck sheet \#20. 
is defined as the average distance between stud and the lateral steel deck sheet (as shown in Fig. 1). Moreover, the studies done by Bonilla (2008), using numerical modeling together with some experimental validation from Jayas \& Hosain (1988), Robinson (1988), Lyons et al. (1994) and Rambo-Roddenberry (2002) concluded that the strong position (SP) is when emid-hr $\geq 59 \mathrm{~mm}$ and the weak position (WP) is considered for emid-hr $<59 \mathrm{~mm}$. Those values are very similar to the value of $56 \mathrm{~mm}$ established by Rambo-Roddenberry (2002).

\section{Shear resistance of stud connectors in steel deck with $76 \mathrm{~mm}$ of height}

Bonilla (2008) carried out an extensive study based upon the processing of results from the numerical simulation of push-out tests and from experimental data reported in the literature by Jayas \& Hosain (1988), Robinson (1988), Lyons et al. (1994) and Rambo-Roddenberry (2002). In light of these results, a new model for predicting the shear resistance of headed stud shear connectors is proposed for steel deck with $76 \mathrm{~mm}$ in height. For different stud positions in the deck rib (SP, WP, StP - see Figs. 1 and 6) various expressions are established and presented in Table-2. In this table, the column termed "Position" refers to the three positions SP, WP and StP of the stud inside the steel deck rib, and each row specifies two proposed expressions for the prediction of the shear resistance of stud connectors ( $Q \mathrm{sc})$.

\begin{tabular}{|c|c|c|}
\hline \multirow{2}{*}{ Position } & \multicolumn{2}{|c|}{ Proposed Expressions } \\
\hline & General expressions & Simplified expressions \\
\hline $1 \mathrm{SP}$ & $Q_{i t}=1.04 \cdot A_{i t} \cdot f_{c}^{0.35} \cdot E_{t}^{0.44} ; \quad R^{2}=0.966$ & $Q_{s c}=0.33 \cdot A_{s c} \cdot \sqrt{f_{c}^{\prime} \cdot E_{t}} ; \quad R^{2}=0.952$ \\
\hline $1 \mathrm{WP}$ & $Q_{x t}=0.81 \cdot A_{2 t} \cdot f_{t}^{0.35} \cdot E_{t}^{0.44} ; \quad R^{2}=0.900$ & $Q_{s c}=0.25 \cdot A_{s c} \cdot \sqrt{f_{c}^{\prime} \cdot E_{c}} ; \quad R^{2}=0.820$ \\
\hline $1 \mathrm{StP}$ & $Q_{u t}=0.89 \cdot A_{u t} \cdot f_{t}^{0.35} \cdot E_{t}^{0.44} ; R^{2}=0.962$ & $Q_{z t}=0.28 \cdot A_{z c} \cdot \sqrt{f_{c} \cdot E_{\varepsilon}} ; \quad R^{2}=0.922$ \\
\hline
\end{tabular}

Note: Single Stud: 1SP: in Strong Position. 1WP: in Weak Position, 1StP: in Staggered Position

Table- 2 reports the predicting models derived from regression analyses and for each expression the statistical coefficient of determination, denoted (R2) ( $R$ squared) is also reported. The (R2) coefficient indicates how well an expression fits the data points available in Figs. 2 to 5 . Also note that 1SP and 1WP mean, respectively, one single stud in strong position and one single stud in weak positions. In Table-2, there are two types of expressions based on the expressions derived by Ollgaard \& et. al., (1971) using the product of the compressive strength of the concrete ( $\left.f^{\prime} c\right)$ and the modulus of elasticity of the concrete (Ec), as well as the cross section area of the steel connector (ASC).

In this article, the expression for solid slabs used by Ollgaard et al. (1971) is modified so as to consider concrete slabs made up with steel deck. The general expressions in Table- 2 are obtained here and show different power coefficients for ( $\left.f^{\prime} c\right)$ and $(\mathrm{Ec})$. The simplified expressions display the product ( $\left.f^{\prime} c \cdot E c\right)$ under a square root which is easier for engineering practice. For all cases, reported in Table-2, the statistical coefficient of determination (R2) is close to unity, therefore, meaning that the data fits very well with the proposed expressions in Table- 2 . Shear resistance of stud connectors in steel deck with $51 \mathrm{~mm}$ of height

As in the previous section, Bonilla (2008) proposes expressions for predicting the shear resistance of stud connections for steel deck with $51 \mathrm{~mm}$ in height. The difference between this case and the case analyzed before (steel deck with $76 \mathrm{~mm}$ in height) is that now, there are even more experimental data available in the literature, such as Rambo-Roddenberry (2002), Lyons et al. (1994) and Sublett et al. (1992).

\begin{tabular}{|c|c|c|}
\hline \multirow{2}{*}{ Position } & \multicolumn{2}{|c|}{ Proposed Expressions } \\
\hline & General expressions & Simplified expressions \\
\hline $1 \mathrm{SP}$ & $Q_{u s}=1.13 \cdot A_{s t} \cdot f_{t}^{0.35} \cdot E_{t}^{0.44} ; \quad R^{2}=0.943$ & $Q_{s c}=0.36 \cdot A_{s c} \cdot \sqrt{f_{c}^{\prime} \cdot E_{c}} ; \quad R^{2}=0.924$ \\
\hline 1WP & $Q_{u t}=0.88 \cdot A_{d z} \cdot f_{t}^{0.35} \cdot E_{t}^{0.44} ; \quad R^{2}=0.861$ & $Q_{s c}=0.27 \cdot A_{s c} \cdot \sqrt{f_{c} \cdot E_{c}} ; \quad R^{2}=0.830$ \\
\hline
\end{tabular}

Note: 1SP: Strong position, single stud, 1WP: Weak position, single stud.

Columns and rows in Table- 3 are organized identically to Table- 2 before. Table-3 reports the predicting models derived from the regression analyses achieved using data from Sublett et al. (1992), Lyons et al. (1994) and Rambo-Roddenberry (2002). In Table-3, there are two expressions (general and simplified) for the prediction of the shear resistance of stud connectors (Qsc). The expressions are similar to those in Table- 2 using the same power coefficients for the concrete parameters $\left(f^{\prime} c\right)$ and $(E c)$. In Table-3, it is interesting to note how the expressions present a higher statistical coefficient (R2), both for the stud placed in SP and in WP, meaning that the data fits well in the proposed equations.

Table-3 does not propose a prediction model for studs in (StP) inside the steel deck ribs with $51 \mathrm{~mm}$ of height as there is no extensive experimental database for studs in such position so as to allow an accurate regression analysis - as was previously done for steel deck with $76 \mathrm{~mm}$ in height. However, even with this limitation, it is believed that the same expressions for StP in Table-2 for steel deck with $76 \mathrm{~mm}$ in height can be proposed.

\section{Studs in the same line position}

Based upon studies carried out by Rambo-Roddenberry (2002), it is apparent that increasing from one to two studs in the same position in a deck rib (see Fig. 6), the resistance of each stud is approximately reduced by $85 \%$ of the shear resistance of a single stud. Such reduction occurs for both SP and WP. Following the same path, Bonilla (2008) carried out similar comprehensive numerical analyses and concluded that the shear resistance of stud increases to $86.9 \%$ (Bonilla, 2008) instead of $85 \%$ when two connectors are set up inside the same rib of a steel deck slab. Comparing Bonilla's numerical studies with the laboratory testes from Rambo-Roddenberry (2002), it can be concluded that they are consistent and very similar.

Therefore, using Rambo-Roddenberry (2002) and Bonilla (2008) results, it is possible to suggest the implementation of a single reduction coefficient $(\propto 2)$ in the predicting expression for the shear resistance of stud so that the number of studs inside the steel deck rib can be taken into account. The reduction coefficient $(\propto 2)$ is suggested to be 0.87 . Moreover, Bonilla (2008) showed that $(\propto 2)$ does not change meaningfully when the steel deck height or the stud positions inside the steel deck rib are considered. Consequently, a value of $\propto 2=$ 0.87 may be used no matter what the steel deck height or the stud position is.

Therefore, in this case, the predicting expression for the 
shear resistance for two headed studs in SP or WP with the respective coefficient $(\propto 2)$ is given by: $\mathrm{Q} 2 \mathrm{sc}-\mathrm{SP}=0.87 \cdot \mathrm{Qsc}$ or $\mathrm{Q} 2 \mathrm{sc}-\mathrm{WP}=0.87 \cdot \mathrm{Qsc}$; where, Q2sc-SP and Q2sc-WP are, the shear resistance when studs are installed in pairs according their positions (SP or WP); Qsc is the shear resistance of just one connector according to its position (1SP or 1WP).

\section{Studs in staggered position}

Similarly, increasing the number from one to two connectors placed inside the steel deck rib but in staggered position (see Fig. 1(c) reduces the shear resistance of studs when compared to the shear resistance of a single connector in (SP). Based upon Lyons et al. (1994) experimental results and the numerical analyses carried out by Bonilla (2008), it is possible to accept a single reduction factor for the shear resistance of the stud also considering variations in: (i) height of the steel deck and (ii) stud diameters. From Bonilla (2008), it can be concluded that the shear resistance of a stud in StP is approximately $84.1 \%$ of the shear resistance when a single stud is placed in SP. Therefore, for steel deck with $51 \mathrm{~mm}$ in height, the following predicting expressions are:

$Q_{s e-S \varphi}=0.84 \cdot\left(0.36 \cdot A_{s z} \cdot \sqrt{f_{c}^{\prime} \cdot E_{\varepsilon}}\right) \approx 0.30 \cdot A_{s z} \cdot \sqrt{f_{\varepsilon}^{\prime} \cdot E_{\varepsilon}}$

From the expression (6) the reduction coefficient $(\propto 1)$ is approximately 0.30 . Applying the same procedure in the case of steel deck with $76 \mathrm{~mm}$ in height, the following predicting expression (6) for the shear resistance of studs in StP are written as:

$$
Q_{s e-S p}=0.84 \cdot\left(0.33 \cdot A_{s e} \cdot \sqrt{f_{c}^{\prime} \cdot E_{\varepsilon}}\right) \approx 0.28 \cdot A_{s \varepsilon} \cdot \sqrt{f_{c}^{\prime} \cdot E_{\varepsilon}}
$$

The last expression (6) matches the last expression reported in Table-2 but, in that case, based upon regression analysis for studs in StP. Undoubtedly, even following two different approaches, in the case of studs in StP the reduction coefficient $(\propto 1)$ is approximately 0.28 .

\section{Results}

\section{Proposed expressions}

Based on the analyses in the section before, expressions can be proposed for the calculation of the shear resistance of stud connectors. Therefore, in this section, a comparison is made for the stud shear resistance calculated using different methods. For steel decks with $\mathrm{hr}=25 \mathrm{~mm}$ or $\mathrm{hr}=38 \mathrm{~mm}$ in height, expression (7) is suggested:

$$
Q_{s t}=\alpha_{2} \cdot 3.08 \cdot e^{0.048 \cdot A_{z z} \cdot F_{0}} \leq 0.8 \cdot A_{s t} \cdot F_{s}
$$

Expression (7) shows adequate prediction as can be seen in Table-4. The experimental value (QSC-test) of the shear resistance of stud connectors is compared with the predicting values (Qsc-EC-4, Qsc-LRFD, Qsc-R-R or Qsc-Prop), respectively, using expressions from the AISC-LRFD (2010), Rambo-Roddenberry (2002) $(\propto 2=0.85)$, the Eurocode-4 (EN-

\begin{tabular}{|c|c|c|c|c|}
\hline \multicolumn{5}{|c|}{$25 \mathrm{~mm}$ or $38 \mathrm{~mm}$ deck height } \\
\hline $\begin{array}{l}\text { Statistical } \\
\text { parameters }\end{array}$ & $\begin{array}{l}Q_{\text {sc-test }} / \\
Q_{\text {sc-LRFD }}\end{array}$ & $\begin{array}{c}Q_{\text {sc-test }} / \\
Q_{\text {sc-R-R }} \\
(\propto 2=0.85)\end{array}$ & $\begin{array}{l}Q_{\text {sc-test }} / \\
Q_{\text {sc-EC-4 }}\end{array}$ & $\begin{array}{c}Q_{\text {sc-test }} / \\
Q_{\text {sc-Prop }} \\
(\propto 2=0.87)\end{array}$ \\
\hline Means & 0.757 & 0.993 & 0.913 & 0.970 \\
\hline Max. Value & 1.008 & 1.104 & 1.148 & 1.102 \\
\hline Min. Value & 0.532 & 0.938 & 0.739 & 0.920 \\
\hline Coeff. Variation & 0.249 & 0.056 & 0.158 & 0.054 \\
\hline $\begin{array}{c}0.85<Q_{\text {sc-test }} / \\
Q_{\text {sc-theo }}<1 \text { (in \%) }\end{array}$ & 41.67 & 58.33 & 8.33 & 66.67 \\
\hline $\begin{array}{c}\mathrm{Q}_{\text {sc-test }} \mathrm{I} \\
\mathrm{Q}_{\text {sc-theo }}<0.85 \text { (in \%) }\end{array}$ & 50.00 & 0.00 & 50.00 & 0.00 \\
\hline
\end{tabular}
1994-1-1:2004) and as proposed here in this paper $(\propto 2=0.87)$.
For steel decks with $38 \mathrm{~mm}<\mathrm{hr} \leq 76 \mathrm{~mm}$ in height, expression (8) is suggested:

$$
Q_{s t}=\alpha_{1} \cdot \alpha_{1} \cdot \alpha_{g} \cdot A_{s t} \cdot \sqrt{f_{t}^{\prime} \cdot E_{s}} \leq 0.8 \cdot A_{s t} \cdot F_{v}
$$

In expression (8), the term $(\propto 1)$ takes into account the stud position (its value can be inferred from a regression model shown in Table 2 and 3 ). The term ( $\propto 2)$ considers the number of connectors inside the steel deck rib. For connectors placed in staggered position, the unit value for $(\propto 1)$ is adopted. The terms $(\propto 3)$ for studs in weak position are inferred from Table-1. See Table-5. In expressions (7) and (8), $f^{\prime} c$ is the compressive strength of the concrete ( $\mathrm{MPa}$ ) and $\mathrm{Fu}$ is the ultimate tensile strength of the material of the stud (MPa). Asc is the area of the stud cross-section (m2), Ec is the concrete Module of Elasticity (MPa) and Qsc is the shear resistance of the stud connector (MN).

Through the expressions (7) and (8), a limit of $0.8 \cdot \mathrm{Asc} \cdot \mathrm{Fu}$ is established as set out in the Eurocode-4 (EN-1994-1-1:2004) and experimental studies carried out by Rambo-Roddenberry (2002) where such limitation is enforced. Moreover, those studies also indicate that the connector is working under a combined stress state of shearing, bending and traction and therefore the limiting of 0.8 .Asc.Fu was established lower than its traction resistance Asc. Fu.

In Fig. 7, the behavior regarding the shear resistance prediction is represented in a graph form based upon the expression (8) here proposed for steel decks with $38 \mathrm{~mm}<\mathrm{hr} \leq 76 \mathrm{~mm}$ in height. Note in Fig. 7 a considerable improvement in the prediction of the shear resistance of stud in front of the existing methods - given the adequate precision observed in Fig. 7. These aspects can be noted in Table- 6 where there is a set of statistical data, indicative of the result patterns through the relation (QSC-test./QSC-theo - where QSC-theo can be Qsc-EC-4 or Qsc-LRFD or Qsc-R-R or Qsc-Prop). The coefficient of variation for the procedure proposed is reported in Table-6, and the value of 18.50 (for $\mathrm{hr}=76 \mathrm{~mm}=3 \mathrm{in}$ ) is the lowest value in comparison to the other methods studied.

Conversely, the average value in the relation (Qsc-test/ Qsc-theo) shows a significant improvement in relation to the non-overestimation of shear resistance of stud connectors if compared to the method in the AISC-LRFD (2010) considered a little more rational than the value in the Eurocode-4 (EN194-1-1:2004), due to its high conservatism in some situations. In other situations, as with studs in an unfavorable position, 
the same methods overestimate the shear resistance of stud connectors.

\begin{tabular}{|c|c|c|c|c|}
\hline \multirow{2}{*}{$\begin{array}{l}\text { Coeffi- } \\
\text { cients }\end{array}$} & \multirow[b]{2}{*}{ Criterion } & \multicolumn{3}{|c|}{ Deck height (hr) } \\
\hline & & $\mathrm{hr} \leq 38 \mathrm{~mm}$ & $\begin{array}{c}38<\mathrm{hr} \leq 60 \\
\mathrm{~mm}\end{array}$ & $\begin{array}{c}60<\mathrm{hr} \leq 80 \\
\mathrm{~mm}\end{array}$ \\
\hline \multirow{3}{*}{$\propto 1$} & $\begin{array}{c}1 \mathrm{SP} \\
\left(\mathrm{e}_{\mathrm{mid}-\mathrm{hr}} \geq 56 \mathrm{~mm}\right)\end{array}$ & - & 0.36 & 0.33 \\
\hline & $1 \mathrm{StP}$ & - & 0.30 & 0.28 \\
\hline & $\begin{array}{c}1 \mathrm{WP} \\
\left(\mathrm{e}_{\mathrm{mid}-\mathrm{hr}}<56 \mathrm{~mm}\right)\end{array}$ & - & 0.27 & 0.25 \\
\hline & & \multicolumn{3}{|c|}{$\mathrm{hr} \leq 80 \mathrm{~mm}$} \\
\hline \multirow{3}{*}{$\propto 2$} & $\begin{array}{l}\text { Single Stud in } \\
\text { SP, WP or StP }\end{array}$ & \multicolumn{3}{|c|}{1.00} \\
\hline & $\begin{array}{l}\text { Pairs of Studs in } \\
\text { SP or WP }\end{array}$ & \multicolumn{3}{|c|}{0.87} \\
\hline & & & $\mathrm{hr} \leq 38 \mathrm{~mm}$ & $\begin{array}{c}38<\mathrm{hr} \leq 80 \\
\mathrm{~mm}\end{array}$ \\
\hline \multirow{5}{*}{$\propto 3$} & \multicolumn{2}{|c|}{ SP, StP - any Gauge } & - & 1.00 \\
\hline & \multirow{4}{*}{ In WP } & Gauge 22 & - & 0.88 \\
\hline & & Gauge 20 & - & 1.00 \\
\hline & & Gauge 18 & - & 1.05 \\
\hline & & Gauge 16 & - & 1.11 \\
\hline
\end{tabular}

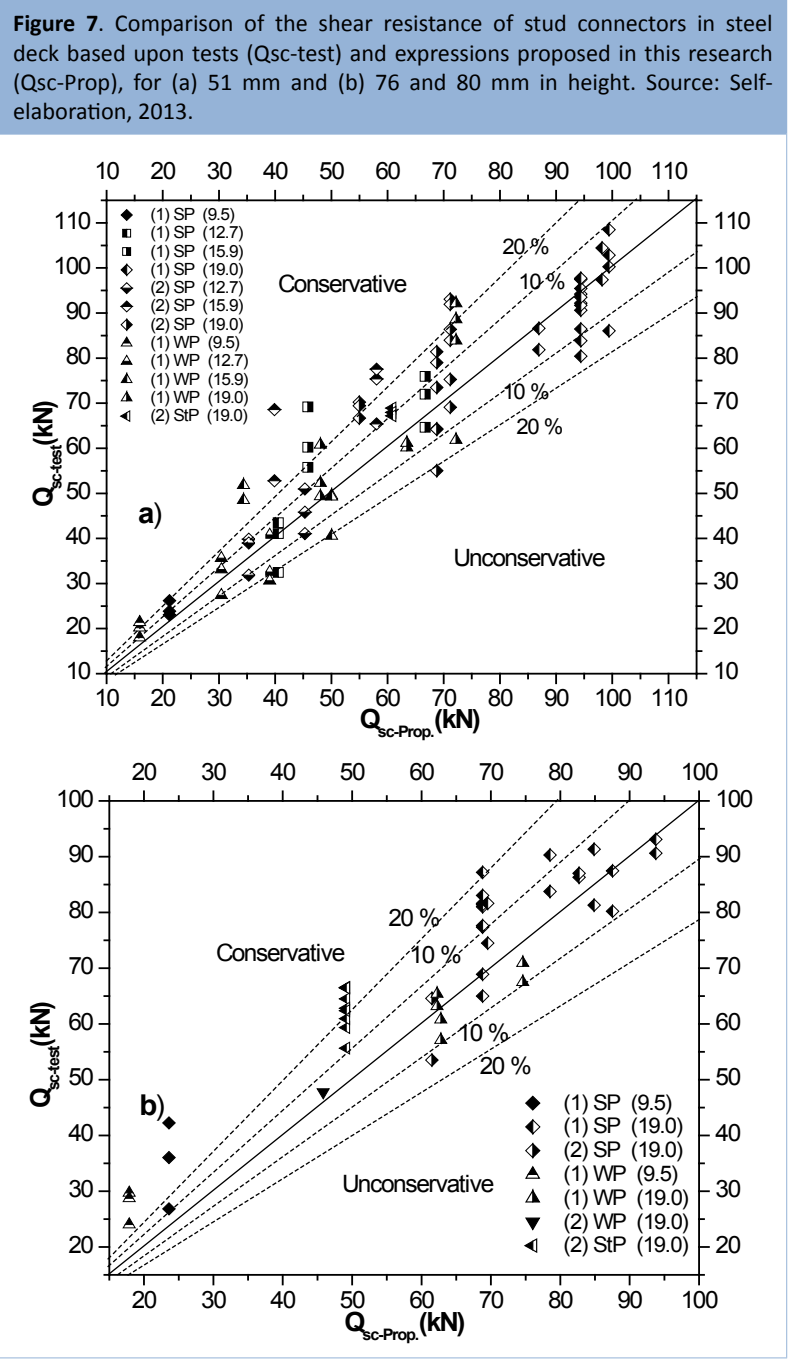

Conversely, the average value in the relation (Qsc-test/ Qsc-theo) shows a significant improvement in relation to the non-overestimation of shear resistance of stud connectors if compared to the method in the AISC-LRFD (2010) considered a little more rational than the value in the Eurocode-4 (EN194-1-1:2004), due to its high conservatism in some situations. In other situations, as with studs in an unfavorable position, the same methods overestimate the shear resistance of stud connectors.

\section{Results Analysis and Discussion}

Examining Table-6, it is important to examine the statistical parameter. From this table, compared to the other methods, the proposed procedure shows a better precision in the determination of the shear resistance of stud connectors especially for studs in unfavorable positions. This can be seen, comparing the proposed procedure predicting results in Fig. 7 with Figs. 3, 4 and 5 where the other procedures, respectively, AISC-LRFD (2010), Eurocode-4 (EN-1994-1-1:2004) and RamboRoddenberry (2002) show a trend towards nonconservative values while the proposed procedure (Fig. 7) shows a trend towards conservative values.

\section{Conclusions}

A simple and new practical calculation procedure based on numerical and experimental results was proposed and improved the precision in the prediction of shear resistance of stud connectors. Statistical analyses show that the new procedure, in comparison with other methods currently used, considerably improves the prediction of shear resistance of stud connectors in steel-concrete composite beams with concrete slab made of steel deck with ribs perpendicular to the longitudinal axis of the steel I-beam section.

The concrete properties have great influence on the shear resistance of stud, mainly when the studs are in strong or in staggered positions. Experimental and numerical results made clear that the stud position is an important factor, and has to be taken into consideration for the calculation of the shear resistance of stud. In increasing steel deck thickness, i.e. steel deck gauge, there is an increase in the shear resistance of stud when studs are placed in weak position.

\section{Acknowledgements}

The authors would like to acknowledge a research grant provided by CAPES (Coordination for the Improvement of Higher Level Personnel, Brazil) and the support given by the University of Brasilia (UnB) to develop this research. 


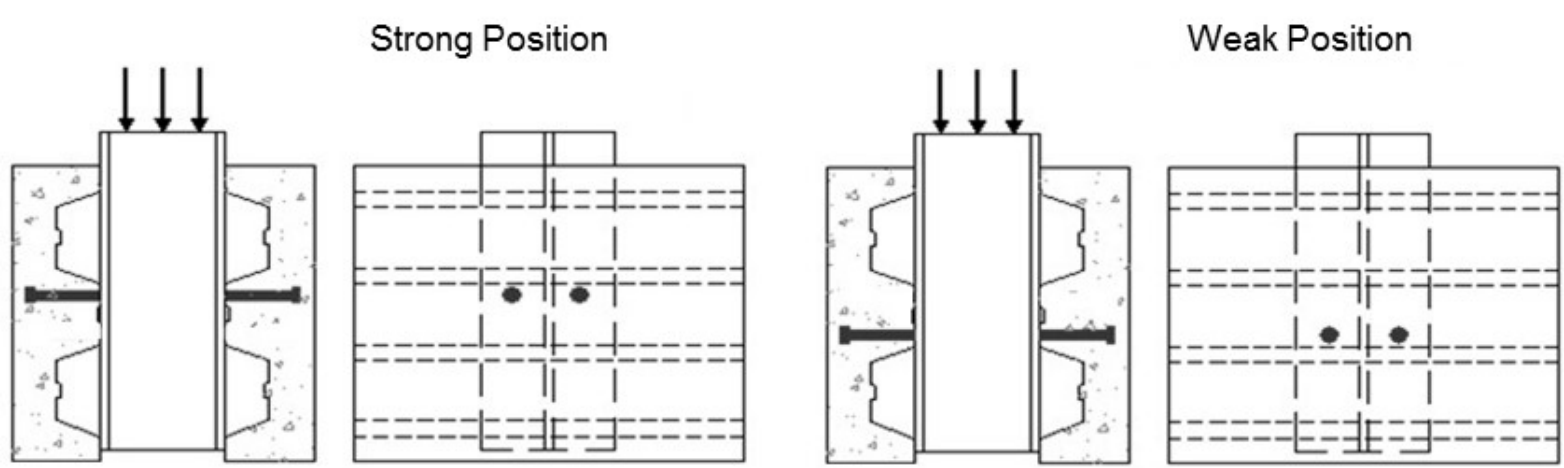

In push-out test

Table 6. Statistical data from results generated using different procedures. Source: Self-elaboration, 2013.

\begin{tabular}{|c|c|c|c|c|c|c|c|c|}
\hline \multirow[b]{2}{*}{$\begin{array}{l}\text { Statistical } \\
\text { parameters }\end{array}$} & \multicolumn{4}{|c|}{$51 \mathrm{~mm}$ Deck Height (2 in) } & \multicolumn{4}{|c|}{76 mm Deck Height (3 in) } \\
\hline & $\begin{array}{l}Q_{\text {sc-test }} / \\
Q_{\text {sc-LRFD }}\end{array}$ & $\begin{array}{c}\mathrm{Q}_{\text {sc-test }} I \\
\mathrm{Q}_{\text {sc-RR }}\end{array}$ & $\begin{array}{l}Q_{\text {sc-test }} / \\
Q_{\text {sc-EC-4 }}\end{array}$ & $\begin{array}{l}\mathrm{Q}_{\text {sc-test }} / \\
\mathrm{Q}_{\text {sc-Prop }}\end{array}$ & $\begin{array}{l}Q_{\text {sc-test }} / \\
Q_{\text {sc-LRFD }}\end{array}$ & $\begin{array}{c}\mathrm{Q}_{\text {sc-test }} / \\
\mathrm{Q}_{\text {sc-RR }}\end{array}$ & $\begin{array}{l}Q_{\text {sc-test }} / \\
Q_{\text {sc-EC-4 }}\end{array}$ & $\begin{array}{l}Q_{\text {sc-test }} / \\
Q_{\text {sc-.Prop }}\end{array}$ \\
\hline Means & 0.92 & 1.04 & 1.20 & 1.09 & 0.90 & 0.99 & 1.22 & 1.14 \\
\hline Maximum Value & 1.24 & 1.48 & 2.09 & 1.72 & 1.49 & 1.64 & 1.88 & 1.79 \\
\hline Minimum Value & 0.63 & 0.73 & 0.70 & 0.78 & 0.56 & 0.62 & 0.72 & 0.75 \\
\hline Coeff. of Variation (\%) & 14.65 & 14.45 & 20.83 & 16.12 & 18.61 & 20.74 & 19.85 & 18.50 \\
\hline $0.85<Q_{\text {sc-test. }} / Q_{\text {sc-theo }<1}(\%)$ & 39.7 & 38.6 & 10.8 & 28.9 & 45.7 & 54.4 & 10.8 & 21.7 \\
\hline $\mathrm{Q}_{\text {sc-test. }} / \mathrm{Q}_{\text {sc-theo }}<0.85(\%)$ & 31.3 & 6.0 & 9.6 & 6.0 & 39.1 & 10.8 & 8.7 & 2.2 \\
\hline
\end{tabular}

\section{References}

AISC-LRFD (2010) Load and Resistance Factor Design (LRFD) Specification for Structural Steel Building. American Institute of Steel Construction (AISC), Inc., Chicago, IL.

Bonilla, J. (2008) Estudio del comportamiento de conectores tipo perno de estructuras compuestas de hormigón y acero mediante modelación numérica, PhD. Thesis, Universidad Central de Las Villas, Sta Clara, Cuba.

Bonilla, J., Larrúa, R., Recarey, C., Mirambell, E., Gómez, A., \& López, M. (2010). Simulación numérica del ensayo push-out para conectores tipo perno de estructuras mixtas en sección viga-losa con lámina nervada. Revista Ingeniería Civil, (157), 109-120.

Bonilla, J., Bezerra, L. M., Larrúa, R, Recarey, C., \& Mirambell, E. (2015). Modelación numérica con validación experimental aplicada al estudio del comportamiento de conectores tipo perno de estructuras compuestas de hormigón y acero. Revista Ingeniería de Construcción, 30 (1), 53-68. doi: http://dx.doi.org/10.4067/S0718-50732015000100005.

EN 1994-1-1 (2004) Design of Composite Steel and Concrete Structures Part 1.1 (2004). European Committee for Standardization, Brussels.

Hernandez, H., Bonilla, J., \& Rodriguez, G. (2014). Estudio del comportamiento de vigas compuestas de hormigón y acero mediante simulación numérica. Revista Ingeniería de Construcción, 29 (1), 5-21. doi: http://dx.doi.org/10.4067/ S0718-50732014000100001.

Jayas, B. S., \& Hosain, M. U. (1988). Behavior of Headed Studs in Composite Beams: Push-out Test. Canadian Journal of Civil Engineering, 15 (2), 240-253.

Johnson, R. P., \& Yuan, H. (1998). Existing Rules and New Tests for Stud Shear Connectors in Troughs of Profiled Sheeting. Proc. Instn Civ. EngrsStructs \& Bldgs, (128), 244-251.
Larrua, R., Caballero, Y., Filiberto, Y., Olivera, I., Guerra, M., Bello, R., \& Bonilla, J. (2009). Aplicación de la inteligencia artificial a la predicción de la capacidad resistente última de las conexiones en estructuras compuestas acero-hormigón, Revista de la Construcción, 8 (2), 109-119.

Lawson, R. M., Lim, J. B. P., \& Popo - Ola, S. O. (2013). Pull-out forces in shear connectors in composite beams with large web openings, Journal of Constructional Steel Research, (87), 48-59.

Lyons, J. C., Easterling, W. S., \& Murray T. M. (1994). Strength of Welded Shear Studs, Report No. CE/VPI-ST 94/07. Virginia Polytechnic Institute and State University, Blacksburg, VA.

Ollgaard, J. G., Slutter, R. G. \& Fisher, J. W. (1971). Shear Strength of Stud Connectors in Lightweight and Normal-Weight Concrete, Engineering Journal AISC, 8(2), 55-64.

Rambo-Roddenberry, M. D. (2002) Behavior and Strength of Welded Stud Shear Connectors, PhD. Thesis, University of Blacksburg, Virginia, EE.UU.

Robinson, H. (1988). Multiple Stud Shear Connectors in Deep Ribbed Metal Deck, Canadian Journal of Civil Engineering, 15 (4), 553-569.

Sublett, C. N., Easterling, W. S., \& Murray, T. M. (1992). Strength of Welded Headed Studs in Ribbed Metal Deck on Composite Joist. Report No. CE/VPI-ST 92/03. Virginia Polytechnic Institute and State University, Blacksburg, VA.

Zheng, T., Lu, Y. \& Usmani, A. (2014). Analytical model for the composite effect of coupled beams with discrete shear connectors, Structural Engineering and Mechanics, 52(2), 369-389. doi: http://dx.doi.org/10.12989/sem.2014.52.2.369. 